\title{
Rapid diagnostic tests correlates with microscopy but not C-reactive protein among HIV positive rural population with malaria in Central Uganda (Research note)
}

B. Silhar (Barbara Silhar)', J. Suvada (Jose Suvada)', G. Mikolasova (Gertruda Mikolasova)', A. Mamova (Alexandra Mamova) ${ }^{1,2}$, M. Belovicova (Maria Belovicova)3 ${ }^{3}$ I. Bartosovic (Ivan Bartosovic) $)^{3}$, V. Krcmery (Vladimir Krcmery)3, T. Hrindova (Tatiana Hrindova)4, J. Ridosko (Jaroslav Ridosko) ${ }^{4}$ P. A. Haij (Peri Ali $H a i j)^{3}$

${ }^{1}$ Health Initiative Association, Buikwe, Uganda

Original Article

${ }^{2}$ Elizabeth University Tropical PhD and MPH Programme, Slovak Republic in Buikwe, Uganda

${ }^{3}$ Migrant Health Programme SEUC and UNMCR Refugee Camp II., Veroia, Greece

${ }^{4}$ Elizabeth University Tropical $\mathrm{MSc} / \mathrm{PhD}$ and Programme

\section{E-mail address:}

peri986@hotmail.com

\section{Reprint address:}

Peri Ali Hajj

St. Elisabeth University refugee health and $\mathrm{MSc} / \mathrm{PhD}$ programme

UNHCR Camp 22

Veroia Greece

Suource: Clinical Social Work and Health Intervention

Volume: 8

Issue: 3

Pages: $58-61$

Cited references: 7

\section{Reviewers:}

George Herdics

School of Management Warsaw University of Management, Poland

Gabriela Lezcano

University of California, San Francisco, USA

\section{Key words:}

Malaria, Rapid diagnostic tests, CRP.

\section{Publisher:}

International Society of Applied Preventive Medicine i-gap

CSWHI 2017; 8(3): 58 - 61; DOI 10.22359/cswhi_8_3_11 (c) 2017 Clinical Social Work and Health Intervention 


\section{Abstract:}

Objectives: To assess the correlation between three diagnostic methods in tropical malaria: Rapid Diagnostic Test (RDT); Microscopy; and C-reactive Protein (CRP) in clinically suspected cases of malaria in HIV positive rural Ugandan population.

Patients and methods: Among 625 cases of clinically suspected malaria, 292 had provided all three types of tests RDT, CRP, plus routine microscopy (RM). Correlation between RTD and RM and CRP and fever was tested with t-test in a HIV positive population in the North Victoria Lake region which is highly endemic for tropical malaria.

Results: Of 74 documented cases, both clinically and in laboratory (19\% of all cases tested by three types of test), 67 had laboratory confirmed malaria (both RTD and microscopy positive). There is a strong correlation between RTD and microscopy (100\% sensitivity and 97\% specificity) but not with CRP, when only $47.5 \%$ of CRP positive cases had RTD and microscopically positive malaria.

\section{Conflict of interest:}

The authors whose names are listed in the title of the article certify that they have NO affiliations with or involvement in any organization or entity with any financial interest (such as honoraria; educational grants; participation in speakers' bureaus; membership, employment, consultancies, or other equity interest), or non-financial interest (such as personal or professional relationships, affiliations, knowledge or beliefs) in the subject matter or materials discussed in this manuscript.

\section{Introduction}

Consumption of antimalarial treatment is increasing after artemisin was introduced as a first line treatment of tropical malaria. (Molnarova et al. 2016). Due to the limited resources in the area of Sub-Saharan Africa (SSA) only parasite based microscopy (PM) was used in the past. (Mamova et al. 2017) After 2010 also rapid point of care dynamic tests were introduced. In a cohort of 90,000 patients in Rwanda after introducing RTD, consumption of antimalarial drugs decreased $5 \mathrm{x}$ such as only $20 \%$ of febrile episodes are confirmed as malaria, the rest were likely simple RTI. (Molnarova et al. 2016)

In Kenya, Tanzania and Uganda a study of almost 600 patients was performed on correlation of febrile episodes due to malaria and CRP positivity and RTD from malaria. (Komlosi et al. 2016) Only 185 patients had malaria and the positivity of RTD plus RM and did not correlate with elevated CRP. Another study in highland Kenya tried to correlate CRP more than $30 \mu \mathrm{g} / \mathrm{ml}$ and documentation of malaria with Neurologic complications. (Szabo et al. 2013) CRP was found in at least 3 cohorts as a poor predictor of malarial etiology, when RDT's demonstrated $95-99 \%$ sensitivity and 93-98\% specificity in comparison to PCR or repeated RM.

The aim of this research note was to assess the correlation between 3 different diagnostic methods for tropical malaria. Rapid diagnostic tests (HRP-RDT), routine microscopy 
(RM) and C-reactive protein (CRP) were correlated in clinically suspected cases of malaria in rural Ugandan population.

\section{Patients and Methods}

Malaria is hyperendemic in the area of Victoria Lake in Central Uganda and is responsible for almost $50 \%$ of all febrile episodes. Due to the availability of artemisin-combined therapy (ACT), almost all cases of febrile episodes receive such therapy. Introduction of RDTs and RM had the aim to decrease unnecessary drug use in this area, with population of about $2-3$ million.

Correlation between RDT and RM and CRP and fever was tested with t-test in patients presenting with fever between March 2013 and December 2016 in Buikwe, Central Uganda.

\section{Results and Discussion}

625 patients in total presented in the OPD with febrile episodes and were clinically suspected as malaria: 292 had provided RDT, CRP plus routine microscopy (RM) and 74 had positive microscopy - Out of these 74 RT positive tests only 66 were confirmed also by the rapid test 8 RDT were false negative (almost 11\%) All patients with positive microscopy results were treated as malaria. All of them received ACT, nobody died or developed complications. Of 74 cases (with RM and positivity) only 27 had CRP $<30 \mu \mathrm{g} / \mathrm{ml}, 12$ had CRP between 30 and 50, and 35 had CRP $>50 \mu \mathrm{g} /$ $\mathrm{ml}$. Similar results were presented in Ugandan, Tanzanian, Kenyan and Rwandan cohorts, (Molnarova, K. Wolf, S. Tenna, M. 2016) The study had failed to prove CRP as a diagnostic factor for malaria. (Mamova, A. et al. 2017, Kweka, EJ. et al. 2011, Komlosi, M. et al. 2017, Szabo, I. et. al. 2013) Specificity and sensitivity for RDTs was $99.2 \%$ and $99.9 \%$ respectively.
There is a statistically significant correlation between RDT and RM, but not with CRP in the patients presenting with fever to medical centers. Therefore, CRP should not be used as a diagnostic method for malaria. Microscopy should not be considered longer as the first. line test for malaria; only did RTD may replace microscopy. If both tests (RTD, MC - microscopy) negative, bacterial infection is more likely and tropical malaria unlikely. The number of false positive microscopy in patients with RTD positive tests was very low.

\section{References}

1. MOLNAROVA $\mathrm{K}$, WOLF S, TENNA M (2016) Highland malaria at the Kiziba UNHCR refugee camps (1950m. a. s.). Clinical Social Work and Health Intervention Vol. 7 No. 32016.

2. MAMOVA A, MIKOLASOVA G, KRCMERY V, MULERA M (2017) Misdiagnosing of malaria as RTI decreased after introduction of RDTs in rural areas of Kenya. Neuroendocrinol Lett 2017; 38(Suppl.1):101-103.

3. KOMLOSI M, AHISHAKIYE A, NIYIBAMPA R, RWASA T, MPAWENAYO A (2017) Comparison between Microscopy and PfHRP2 based RDT for diagnosing Tropical Malaria in Febrile Patients in Mesoendemic Malaria Transmission Area of Eural Burundi, among Internally Displaced Populations after Tribal Conflicts. Clinical Social Work and Health Intervention Vol. 8 No. 22017.

4. KWEKAEJ, LOWASSAA, MSANGI S, KIMARO EE, LYATUU EE, MWANG`ONDE BJ, MAHANDE AM, MAZIGO HD (2011) Low sensitivity of ParaHIT-f rapid malaria test among patients with fever in rural health centers, Northern Tanzania. J Infect Dev Ctries. 2011 Mar 21; 5(3): 204-8.

5. KIMULI D,CZARNECKI P, MIKLOSKOVA M, SPANIK S, BRYNDZAK P ET AL 
(2016) Social pathology II. WMU WARSAW. 2016. 455 pp.

6. BUHALATA SN, MASSAGA JJ (2011) Performance of ParaHit and OptiMAL tests in the diagnosis of malaria in Mwanza, north-western Tanzania. Tanzan J Health Res. 2011 Jan; 13(1): 48-53.
7. SZABO I, KULKOVA N, SOKOLOVA J, MIKOLASOVA G, SUVADA J, KALAVSKA A, DOBRODENKOVA S, MATEICKA F, KAFKOVA J, NKOWA I (2013) Neurologic complications and sequellae of infectious diseases in Uganda and Kenya: Analysis of 288 cases from two rural hospitals. Neuroendocrinology letters, 2013, Vol 34. Supplement 1, 28-31. 